\title{
Carbon Dioxide Assisted Subcision in the Treatment of Adherent Localized Scars
}

\author{
Georgia Lee SK \\ Department of Medical Practice, TLC Lifestyle Practice, Singapore
}

\section{Email address:}

tlcfc@singnet.com.sg

\section{To cite this article:}

Georgia Lee SK. Carbon Dioxide Assisted Subcision in the Treatment of Adherent Localized Scars. Journal of Surgery. Vol. 6, No. 3, 2018, pp. 78-81. doi: 10.11648/j.js.20180603.15

Received: April 19, 2018; Accepted: May 25, 2018; Published: June 12, 2018

\begin{abstract}
Modified subcision assisted with Carbon Dioxide insufflation is described in 2 patients; one with post acne scar and another with adhesion following liposuction. Both subjects have satisfactory results after 3 fortnightly sessions. The Carbon Dioxide flow controlled by the flow rate and procedurist's maneuvering adjusted to the size and positon of the scars help to separate the underlying fibrotic bands allowing the reach beyond the length of the subcising device; in this case being a $30 \mathrm{G} 1 / 2$ needle. The results and recovery is being compared with traditional subcision and possible benefits of Carbon Dioxide assisted subcision are discussed.
\end{abstract}

Keywords: Carbon Dioxide, Scar, Subcision

\section{Introduction}

Scars can occur from tissue injury to the skin, as a result of acne, infection, injury or surgery. Subcision remains an important aspect of treatment to improve the appearance of rolling scars [1].

The technique as described by Orentreich [2] is a minor surgical procedure commonly prescribed for treating depressed scars and adhesions. A hypodermic needle is inserted through the skin surface and its sharp edges manoeuvred under the affected area to make subcuticular cuts in a fan like manner. The principle of this incisionless procedure is to break down the fibrotic tissue, which tether the scar to the underlying subcutaneous tissue. The depression is lifted by the releasing action of the procedure, a small hematoma is intentionally created to act as a filler to enhance wound healing.

However, with traditional subcision, there is significant downtime with bruising and persistent erythema and sometimes, over correction [1].

Carboxytherapy has been used to treat localised adiposity [3], post liposuction irregularity [4], chronic wounds [5], skin laxity, cellulite [6-7], striae [8] dark under circles [9], and scars [10]. $\mathrm{CO}_{2}$ therapy is administered subcutaneously for lipolysis [3] or intradermally using a programmable $\mathrm{CO}_{2}$ therapy apparatus (Carbomed $\AA$, Carbossi Italy) and disposable $32 \mathrm{G}$ needles. The gas is allowed to be infused over the whole treated area with the endpoint being successful release of the adherent fibrotic tissue visualised by the medical staff. It is believed that its mechanism of action is twofold. First, the mechanical injection of the $\mathrm{CO}_{2}$ causes interruption of surrounding connective or scar tissue through direct mechanical destruction. Secondly, $\mathrm{CO}_{2}$ induces vasodilatation and stimulates an inflammatory response that increases collagen growth and tissue remodelling thus improving the skin texture [5]. Moreover, with the flow of the $\mathrm{CO}_{2}$, subcision beyond the length of the needle is possible and this can be applied to larger adherent scars. Hence, carboxytherapy can be an effective adjuvant treatment in subcision of localised adherent scars.

\section{Method}

Case1:

A 27-year old woman presented with a large $1 \mathrm{~cm}$ deep scar from a solitary pimple which had been treated with intralesional steroid injection by another practitioner 2 months previously. A modified technique with infusion of Carbon Dioxide gas was carried out with informed consent.

The area was prepared with application of topical anesthetic 
EMLA 5\% (Eutectic mixture of local anaesthetics: Lidocaine $25 \mathrm{mg}$, Prilocaine $25 \mathrm{mg}$ / gram).

The scar and surrounding area was thoroughly cleansed with Chlorhexidine $0.05 \%$ (Baxter) and $\mathrm{CO}_{2}$ was infused intradermally into the scar using the Carbomed Programmable Automatic Carbon Dioxide Therapy apparatus (Carbossi, Italy) and $30 \mathrm{G} 1 / 2,0.3 \times 13$ microlance needles. The infusion velocity administered was $50 \mathrm{cc} / \mathrm{min}$ and the total quantity of $\mathrm{CO}_{2}$ infused was less than 10cc. Subcuticular fan like sweeping cuts was made under the scar. The procedurist's finger from the non-injecting hand is placed just beyond the margin of the scar to control the flow of the gas. The whole procedure took less than 15 seconds.

A total of 3 sessions of $\mathrm{CO}_{2}$ assisted subcision of the scar was performed at 2 weekly interval.

Case 2:

A 30-year old woman required treatment for post-liposuction irregularity and scarring following ultrasound-assisted liposuction of her abdomen 3weeks before.

The injection entry area was thoroughly cleansed with Isopropyl Alcohol 70\% (Webcol) and $\mathrm{CO}_{2}$ was infused intradermally from the lower outer aspect of the area of tethering using the Carbomed Programmable Automatic Carbon Dioxide Therapy apparatus (Carbossi, Italy) and 30G $1 / 2, \quad 0.3 \times 13$ microlance needles. The infusion velocity administered was $100 \mathrm{cc} / \mathrm{min}$ and the total quantity of $\mathrm{CO}_{2}$ infused was between $300-500 \mathrm{cc}$. By controlling the flow of the gas with the non-injecting hand, the gas was diverted to right under the large area of scarring from just one injection entry point.

A total of 3 sessions of $\mathrm{CO}_{2}$ assisted subcision over the scar was performed at 2 weekly interval. The appearance of her preexisting striae has also shown improvement from the same treatment.

\section{Results}

Case1:

There was some immediate swelling with significantly less hematoma compared to traditional subcision. Scar tissue is released with less subcuticular cuts compared to traditional subcision as the $\mathrm{CO}_{2}$ gas has a better and more even reach compared to traditional subcision with needle alone.

Two weeks later (Figure 2), there was significant scar release and no noticeable erythema as there had been minimal bruising compared with the traditional technique. Figures 5-7 illustrate typical results on another 37 year old female patient with a similar lesion treated conventionally. The improvement after the $3^{\text {rd }}$ session (Figure 4 ) provided satisfactory results for the patient and negated the need for further laser refinement of the affected area.

[Figures 1 - 4 and 5 - 7 near here]

Case 2:

Two weeks after the $3^{\text {rd }}$ session, (Figure 9), there was significant adhesion release. Although there is still irregularity from the liposuction, patient is satisfied with the results and did not need further treatments.

[Figures 8 and 9 near here]
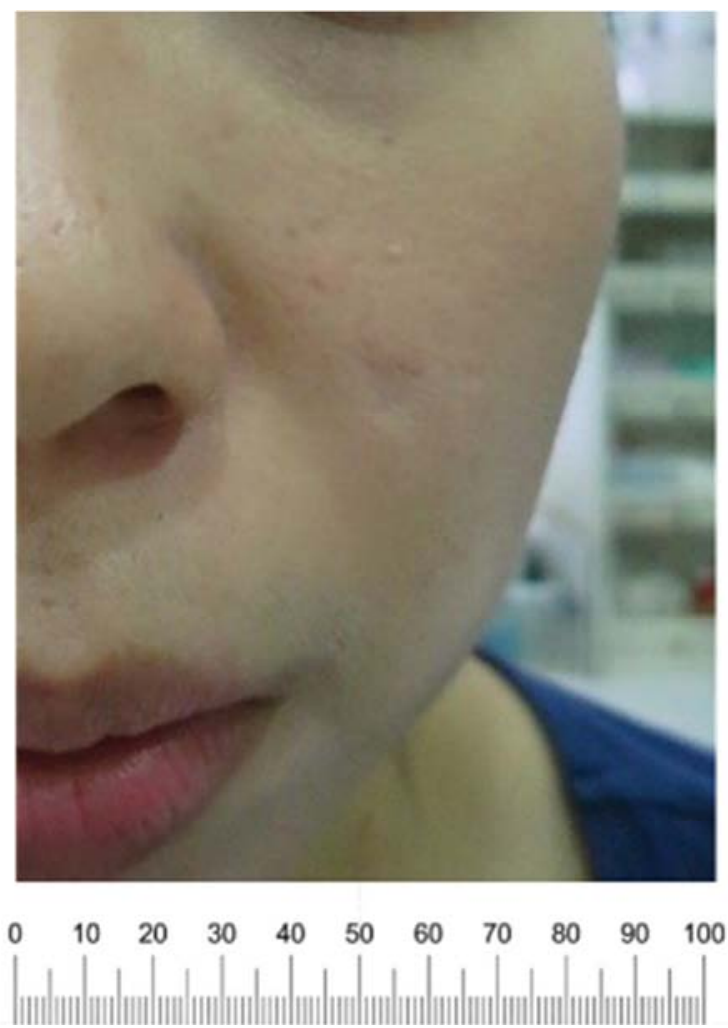

Figure 1. 2 months old scar. Post acne.
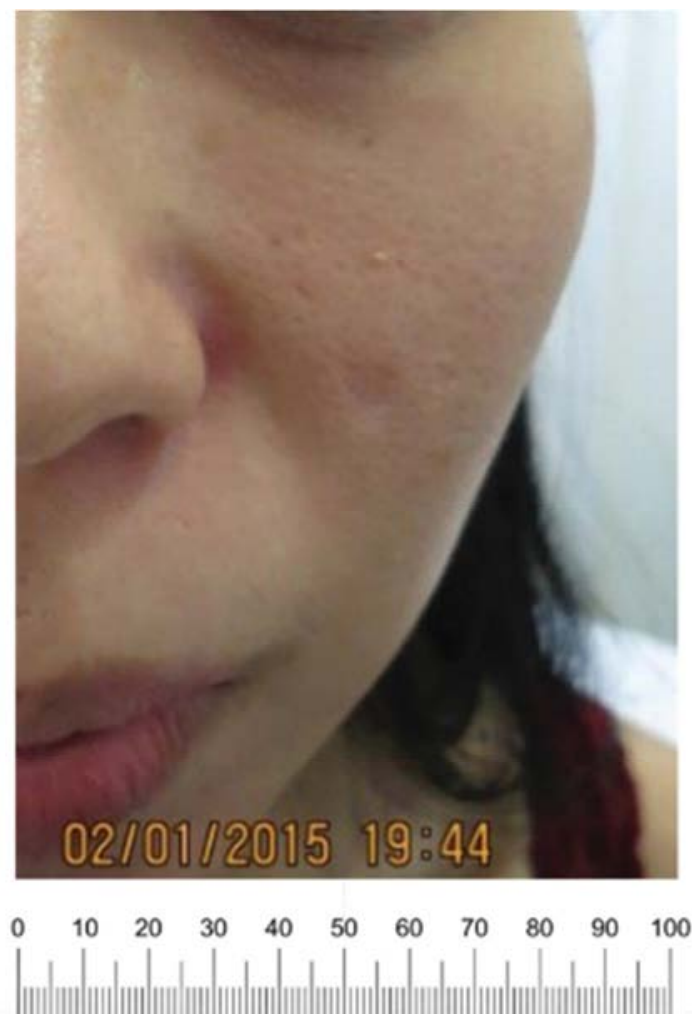

Figure 2. 2 weeks after $1^{\text {st }} \mathrm{CO}_{2}$ assisted subcision. 

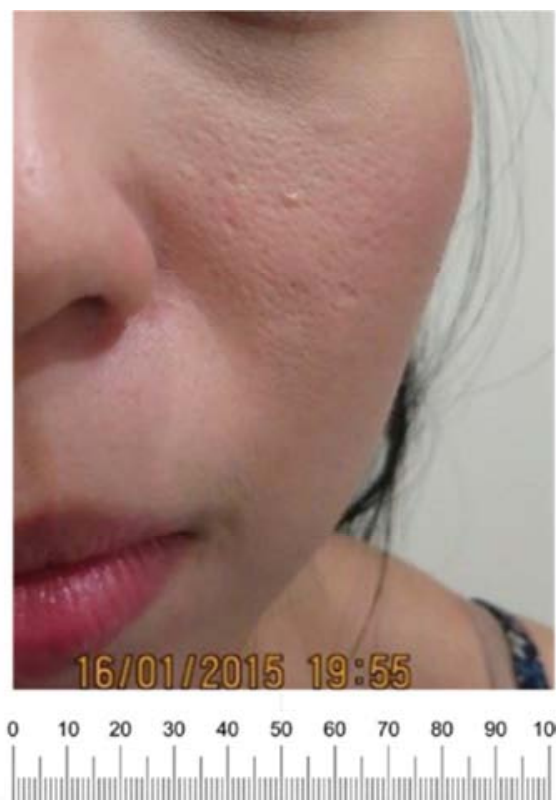

Figure 3. 2 weeks after $2^{\text {nd }} \mathrm{CO}_{2}$ assisted subcision.

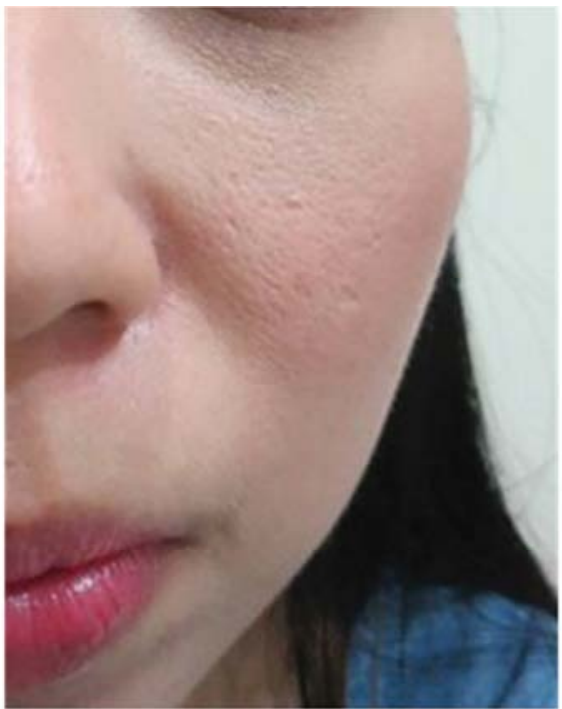

$\begin{array}{lllllllllll}0 & 10 & 20 & 30 & 40 & 50 & 60 & 70 & 80 & 90 & 100\end{array}$

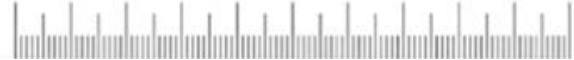

Figure 4. 2 weeks after $3^{\text {rd }} \mathrm{CO}_{2}$ assisted subcision.

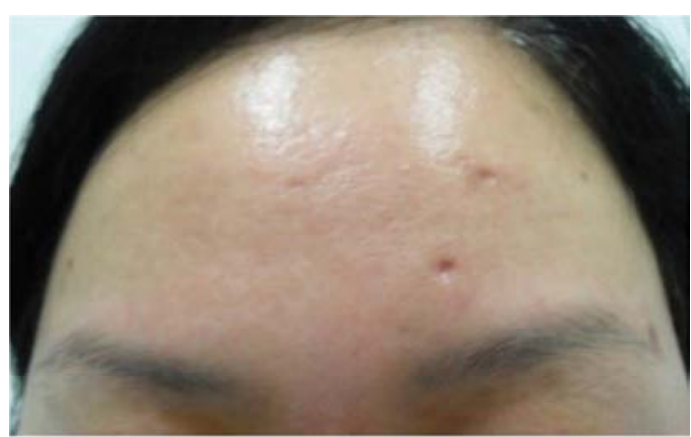

$\begin{array}{lllllllllll}0 & 10 & 20 & 30 & 40 & 50 & 60 & 70 & 80 & 90 & 100\end{array}$

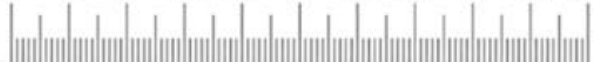

Figure 5. Before traditional subcision.

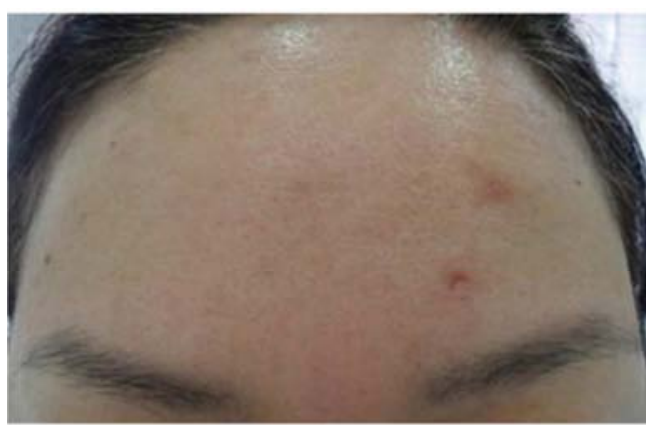

$\begin{array}{lllllllllll}0 & 10 & 20 & 30 & 40 & 50 & 60 & 70 & 80 & 90 & 100\end{array}$

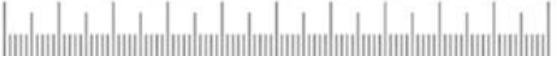

Figure 6. 3 weeks after $1^{\text {st }}$ traditional subcision.

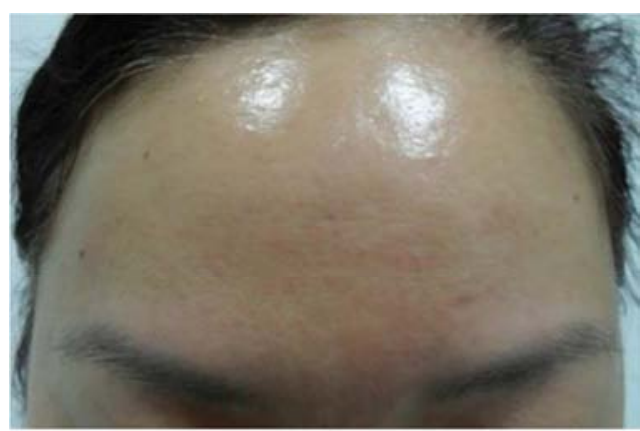

$\begin{array}{lllllllllll}0 & 10 & 20 & 30 & 40 & 50 & 60 & 70 & 80 & 90 & 100\end{array}$

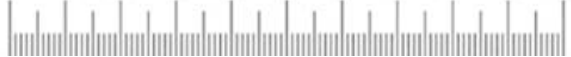

Figure 7. 6months after $2^{\text {nd }}$ traditional subcision

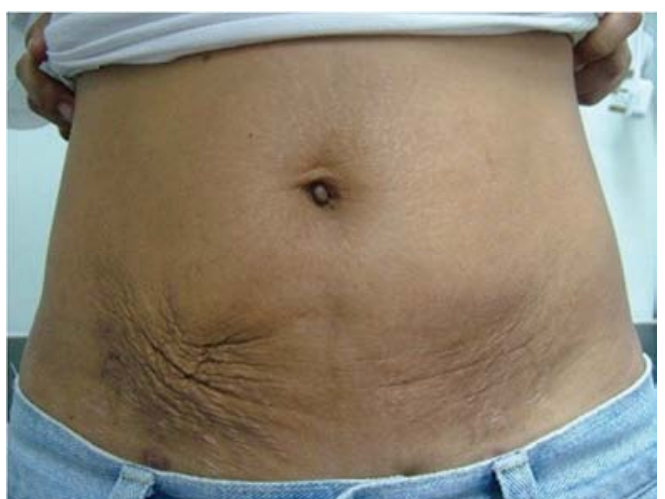

Figure 8. 3weeks after liposuction.

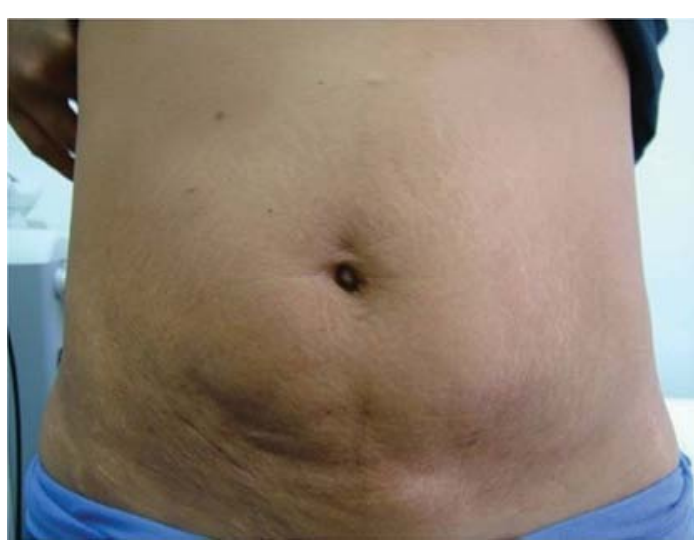

Figure 9. 2 weeks after $3^{\text {rd }} \mathrm{CO}_{2}$ assisted subcision. 


\section{Discussion}

Carbon Dioxide is a non-toxic gas that is widely used in laproscopic surgery and the treatment is affordable. Localized swelling due to $\mathrm{CO}_{2}$ usually resolves within 30 minutes. This duration is similar to that reported by Ozan Balik et al who reported localized swelling lasting up to $48 \mathrm{~h}$ when air is substituted in an experiment involving Wistar rats [11].

Compared to the traditional subcision technique, possible advantages include reduced downtime from bruising and treatment beyond the length of the needle. With reduced bruising from $\mathrm{CO}_{2}$ assisted subcision, less initial nodularity accompanying traditional subcision is also observed [12], thus allowing a shorter timeline leading to patient's satisfaction. Subcision with $\mathrm{CO}_{2}$ infusion allows for reach beyond the length of the needle is an advantage for larger scars, this is akin to the same principle when Carbon Dioxide therapy is being used for reducing irregularity from liposuction [4] and cellulite $[7,13]$. The distension of the tissue caused by the gas triggers tissue repair and regeneration processes with neovascularization and remodeling of the extracellular matrix [7] and this contributes to the final results of the scars being treated $[10,14,15]$.

The flow velocity for patient in case 1 was lower at $50 \mathrm{cc} / \mathrm{min}$ as the scar is small and flow control is needed to prevent over-subcision beyond the margins of the smaller scar. Topical anaesthesia was used as subcision over facial area is usually uncomfortable for patients. A higher flow rate at $100 \mathrm{cc} / \mathrm{min}$ is used for the patient in case 2 as higher mechanical force is needed to release the tighter and larger adhesion. For $\mathrm{CO}_{2}$ infusion over body areas, topical anaesthesia is not usually used as discomfort to patients is generally well tolerated. The total volume used is determined by visualization of the scar release during the procedure whilst using the non-injecting hand to minimise flow beyond the affected area. For both cases, repeated sessions were performed at 2 weekly intervals with the endpoint being visible clinical release of the adhesion and patients' satisfaction.

\section{Conclusion}

Compared to traditional subcision, this Carbon Dioxide assisted technique results in less bruising and post treatment nodularity. The erythema contributed by the vasodilatation effect and crepitus from the Carbon Dioxide gas do not last beyond an hour. Due to the wider reach of the gas, this procedure can be useful for larger areas of post-surgical or post traumatic scarring or irregularity. Further experience is required to document the promise of reduced trauma and shorter recovery time and possibly a better outcome from subcision with Carbon Dioxide induced angiogenesis and collagen remodeling. So far our preliminary results suggest this technique is safe, effective and amenable to training.

\section{Disclosure of Interests}

The author does not have any conflicts.

\section{References}

[1] Alam M., Omura N, Kaminer MS. Subcision for acne scarring: technique and outcomes in 40 patients. Dermatol Surg. 2005; 31:310-7.

[2] Orentreich DS, Orentreich N. Subcutaneous incisionless (subcision) surgery for the correction of depressed scars and wrinkles. Dermatol Surg. 1995; 21:543-9.

[3] Brandi C, D'Aniello C, Grimaldi L, Bosi B, Dei I, Lattarulo P, et al. Carbon dioxide therapy in the treatment of localized adiposities: clinical study and histopathological correlations. Aesthet Plast Surg. 2001; 25:170-4.

[4] Brandi C, D’Aniello C, Grimaldi L, Caiazzo E, Stanghellini E. Carbon dioxide therapy: effects on skin irregularity and its use as a complement to liposuction. Aesthet Plast Surg. 2004; 28(4):222-5.

[5] Brandi C, Grimaldi L, Nisi G, Brafa A, Campa A, Calabrò M, et al. The role of carbon dioxide therapy in the treatment of chronic wounds. In Vivo. 2010; 24(2):223-6.

[6] Koutna N. Carboxytherapy - new, non-invasive method of aesthetic medicine. Cas. Lek. Cesk. 2006; 145(11):841-3.

[7] Pianez LRG, Custódio FS, Guidi RM, de Freitas JN, Sant'Ana EM, et al. Effectiveness of carboxytherapy in the treatment of cellulite in healthy women: a pilot study. Clin Cosmet Investig Dermatol. 2016; 9: 183-190.

[8] Podgórna K., Kołodziejczak A., Rotsztejn H et al. Cutometric assessment of elasticity of skin with striae distensae following carboxytherapy. Journal of cosmetic dermatology (2017).

[9] Paolo F, Nefer F, Paola P, Nicolò S. Periorbital area rejuvenation using carbon dioxide therapy. J Cosmet Dermatol. 2012; 11(3):223-8.

[10] Nach R, Zandifar H, Gupta R, Hamilton. Subcutaneous carboxytherapy injection for aesthetic improvement of scars. Ear Nose Throat J. 2010; 89(2):64-6.

[11] Ozan Balik, Mustafa Yilmaz, Alper Bagriyanik. Does carbon dioxide therapy really diminish localized adiposities? Experimental study with rats. Aesth Plast Surg 2011; 35:470-4.

[12] Gozali MV, Zhou B. Effective Treatments of Atrophic Acne Scars. J Clin Aesthet Dermatol. 2015 May; 8(5): 33-40.

[13] Lee Georgia SK. Carbon Dioxide Therapy in the Treatment of Cellulite: An Audit of Clinical Practice. Aesthetic Plast Surg. 2010; 34(2):239-43.

[14] Maia-Figueiró TL, Odashiro AN, Menezes GP, et al. Semi-quantitative histological analysis of the effect of intense pulsed light (IPL) and carbon dioxide $\left(\mathrm{CO}_{2}\right)$ intradermic injection on fibroblast and collagen proliferation in the skin of Wistar rats. J Cosmet Dermatol Sci Appl. 2012;02(03):164 173.

[15] Pinheiro NM, Crema VO, Millan BM, Carvalho FA, Mendonça AC. Comparison of the effects of carboxytherapy and radiofrequency on skin rejuvenation. $\mathrm{J}$ Cosmet LaserTher. 2015;17(3):156-161. 